\title{
PROJETO DE PRODUTO DE ALTA COMPLEXIDADE TECNOLÓGICA: DESENVOLVIMENTO INTEGRADO DE CAMA HOSPITALAR
}

\author{
Gil Fernandes Brito \\ PPDESDI-UERJ \\ gilfcbrito@gmail.com \\ Frank Barral \\ PPDESDI-UERJ \\ frank.barral@terra.com \\ Luiz Vidal Gomes \\ PPDESDI-UERJ \\ luizvidalgomes@gmail.com
}

\begin{abstract}
Resumo: O objetivo deste artigo é mostrar como um grande número de variáveis, distribuídas por amplo espectro de conhecimentos, pode vir a ser encarado pelos profissionais do design industrial envolvidos no desenvolvimento de um produto de Alta Complexidade Tecnológica (ACT): uma cama hospitalar eletromecânica. Inicialmente o processo se utilizou de pesquisa de caráter exploratório realizada na internet e de visitas a feiras de equipamentos médico hospitalares. A partir dessa análise preliminar, observou-se que o processo criativo que iria gerar o produto final era claramente diverso daquele seguido pelos caminhos da criação de produtos mais simples. Esse projeto recebeu insumos de diferentes fontes como a engenharia, a ergonomia, e também dos profissionais da área médica, levando em consideração fatores econômicos, sociais e psicológicos, tudo coordenado por um plano de trabalho detalhado em fases e de técnicas de gerenciamento. Fatores como a estrita necessidade da observação de normas técnicas que regem a certificação de produtos hospitalares e uma preocupação com o custo e a durabilidade do produto, aumentaram a complexidade da tarefa de se conceber semelhante equipamento. Isto tudo ficou a cargo de uma equipe profissional multidisciplinar fixa, mas que muitas vezes no transcorrer do projeto necessitou de interagir com outros profissionais que foram temporariamente agregados a ela. $O$ projeto resultante combinou a necessidade de inovação com um trabalho de gestão atenta e equilibrada de inúmeros fatores muito diversos entre si que moldaram a configuração final. Dúvidas e impasses surgidos durante o desenvolvimento foram superados por meio de reuniões técnicas e a realização de testes funcionais com modelos e mocapes. Concluiu-se que um produto de Alta Complexidade Tecnológica (ACT) como uma cama hospitalar eletromecânica não pode ser concebido por meio de rasgos instantâneos ou dramáticos de imaginação, mas se configura, sim, como resultado de um trabalho progressivo, metódico, coletivo e integrado.
\end{abstract}


Palavras-chave: design e método, design de produto industrial, alta complexidade tecnológica, atuação do designer industrial.

\begin{abstract}
The purpose of this article is to show how a large number of variables, distributed broad spectrum of knowledge, could be seen by the professionals of industrial design involved in the development of a product of High Technology Complexity (ACT): an electro-mechanical hospital bed. Initially the process used was exploratory research carried out on the internet and visits to hospital medical equipment tradeshows. From this preliminary analysis, it was observed that the creative process that would generate the final product was clearly different from that followed in the ways of creating simpler products. This project received inputs from different sources such as engineering, ergonomics, and also the medical professionals, taking into account economic, social and psychological factors, all coordinated by a detailed work plan in phases and management techniques. Factors such as the strict necessity of observing technical rules governing the hospital product certification and a concern with the cost and durability of the product increased the complexity of the task to design similar equipment. All this was done by a fixed multidisciplinary professional team, but often in the course of the project needed to interact with other professionals temporarily aggregated to it. The resulting design combined the need for innovation with a careful and balanced management work of many very different factors together have shaped the final configuration. Questions and dilemmas that arise during the development were overcome through technical meetings and functional tests with models and mocapes. It was concluded that a product of High Technology Complexity (ACT) as an electromechanical hospital bed cannot be conceived through instant or dramatic flashes of imagination, but it is configured, but, as a result of progressive work, methodical, collective and integrated.
\end{abstract}

Key Words: design and method, industrial product design, high technological complexity; practice of the industrial designer.

\title{
1. INTRODUÇÃO
}

Costuma-se iniciar reuniões acadêmicas e gerenciais de projeto de produto, falando dos aspectos disciplinares e interdisciplinares existentes entre, pelo menos, Nove Profissões do Design. Inicialmente, em meados da década de 1990, essa ideia surge justo para explicar o posicionamento projetual de engenheiros, arquitetos e desenhistas industriais diante do trabalho de planejamento de produto, em cursos de pós-graduação. Por volta de 2005, apresentações gráfico-visuais já haviam sido elaboradas para ilustrar palestras abordando o tema em Semanas Acadêmicas de Pesquisa e Extensão em cursos de Design. Contudo, antes de 2010, o artigo Profissões do Design no Brasil: aspectos na formação vocacional do designer foi apresentado oficialmente em evento acadêmico-científico e em curso de atualização em Desenho Industrial, ambos ocorridos no sul do país. Em todas as ocasiões, alertava-se que profissionais criativos - fossem estes engenheiros, arquitetos, desenhistas industriais - 
quando em reuniões de trabalho para desenvolvimento de projeto de produto complexo, deviam compreender as suas funções como sujeitos cuja criatividade necessita ser orientada, planejada, compartilhada, tal como sugeria Bruce Archer, em 1974. Os designers, que desejem desempenhar papéis condizentes com sua capacitação, não podem deixar de considerar as nuances e interfaces que possuem com outras atividades também criativas e projetuais, a saber: Administração, Arquitetura, Arte, Engenharia, Ergonomia, Mercadologia, Moda, Publicidade, e, mais, Desenho Industrial. Só e somente assim, é possível compreender o que é Design, quando adjetivado, particularmente, "industrial".

Mas o que é, na prática, Design Industrial? Um ultrapassado estilo de arte aplicada a produtos de produção em massa? International Design? Rational Design? Radical Design? Streamlining Design? Utilitarian Design? (FIELL \& FIELL, 2006). Considere-se, particularmente, os artefatos eletrônicos mais cobiçados da atualidade e sempre presentes nas mãos de milhões de usuários, i.e., smartphones, que são um bom exemplo de Desenho Industrial. Pois a tecnologia de informação que nele há pouco valeria, caso o desenho de sua forma não partisse de bom projeto de produto. Indaga-se, ainda: Mas o que é, teoricamente, Design Industrial? Em 2015 o World Design Organization, WDO (antigo ICSID), apresentou a mais nova definição sobre Industrial Design, formulada em Seul, Coréia do Sul:

Desenho Industrial (DI) é um processo estratégico de resolução de problemas que impulsiona a inovação, constrói o sucesso do negócio e leva a uma melhor qualidade de vida através de produtos originais, sistemas, serviços $e$ experiências. O Desenho Industrial preenche a lacuna entre o que é e o que não é possível. É uma profissão transdisciplinar que aproveita a criatividade para resolver problemas e criar coletivamente soluções com a intenção de melhores produtos, sistemas, serviços, experiências ou negócios. No seu âmago, o Desenho Industrial fornece visões mais otimistas do olhar para o futuro, reconfigurando problemas e transformando-os em oportunidades. O DI liga inovação, tecnologia, investigação, empresas e clientes para fornecer novo valor e vantagem competitiva no âmbito econômico, social e ambiental.

Em outras palavras, adaptadas de texto extraído da página do ICSID/WDC (www.icsid.org), pode-se destacar que "Desenho Industrial continua sendo uma profissão envolvida em processos estratégicos, econômicos, tecnológicos e comerciais, tratando-se de atividade projetual focada e capaz de auxiliar na identificação de problemas na cultura material, pois demanda criatividade e inovação aplicada a produtos industriais de consumo (e.g., ambientes, artefatos); de capital (e.g., máquinas e ferramentas); de serviços (e.g., sistemas comunitários)."

Diferentemente de outros profissionais do Design, os designers industriais quando projetam novos produtos, obrigatoriamente, colocam o ser humano no centro de seus processos criativos. Designers industriais são, em geral, projetistas anônimos, pois, como membros de uma equipe, orientam-se antropocentricamente, logo, um tipo de ofício que nada ou pouco tem a ver com o trabalho pessoal, ego-centrado, de um determinado tipo de "design autoral". É, portanto, desse trabalho em equipe que este artigo trata. 


\subsection{Produtos de Baixa, Média e Alta Complexidade Tecnológica}

Em 1982, a pedido do CNPq, o designer Eduardo Barroso Neto organizou o livro Desenho Industrial: Desenvolvimento de Produtos. Nas páginas introdutórias, encontram-se informações que auxiliam compreender a pergunta: Por que um projeto é complexo? Através de um quadro hierárquico, Barroso Neto responde que, dentro do vasto campo de atuação do Design Industrial, algumas searas se diferenciam de acordo com o grau de complexidade tecnológica de cada produto projetado, requerendo, assim, desde o trabalho do designer individual - design autoral- até ao trabalho do designer coletivo, de atuação indispensavelmente interdisciplinar - design industrial. Por exemplo, na categoria de projeto de produtos de Baixa Complexidade Tecnológica (BCT), na qual o designer autoral se posiciona bem, estão desde o desenho para artefatos de couro e calçados, vestuário/assessórios de moda, até louças e talheres, cutelaria e ferragens, passando por embalagens e brinquedos. Por Média Complexidade Tecnológica (MCT), ou seja, por um tipo de projeto que requer a participação de distintos designers industriais, especialistas em certos segmentos de produtos, podemos agrupar o projeto para "mobiliário doméstico, componentes para construção, estandes para feiras e exposições; equipamentos de mobiliário urbano; mobiliário técnico e profissional; equipamentos de uso público; instrumentos musicais; embalagens de segurança; sistemas e equipamentos de sinalização". Por fim, e talvez mais importante, econômica e tecnologicamente, para o Design Industrial, estão os produtos de Alta Complexidade Tecnológica (ACT), aqueles que requerem a participação do designer industrial equipes, por vezes, subdivididas em vários grupos de profissionais interdisciplinares. É nessas equipes de profissionais (e.g., engenheiros, arquitetos, desenhadores; urbanistas, publicitários, mercadologistas) que se contrata 0 desenvolvimento de projeto para os desenhos de produto, a saber: "eletrodomésticos; instrumentos óticos; equipamentos de laboratório; veículos e assessórios de transporte; veículos e assessórios de carga: máquinas e implementos agrícolas; ferramentas; equipamentos médico-hospitalares" (apud BAROSSO NETO, 1982).

A cama hospitalar é um equipamento médico-hospitalar que hoje apresenta alta complexidade tecnológica no planejamento e desenvolvimento do seu projeto e também na sua fabricação. A sua relevância para as rotinas de tratamento de pacientes dentro de uma unidade de cuidados de saúde e a sua perfeita integração ao seu ambiente de trabalho são de especial importância. Um equipamento inadequado, resultante de um processo de desenvolvimento de produto mal concebido, poderá afetar negativamente o desempenho de toda equipe de profissionais de saúde, com consequências nefastas para o próprio paciente. Soma-se a esse contexto mais técnico e funcional, o fato de que este é um produto de custo elevado e os seus operadores têm uma grande expectativa em relação à sua vida útil (apud SANTOS; HORTA, 2005).

\section{DESENVOLVIMENTO}

O início do planejamento deste projeto foi realizado por meio de pesquisa de caráter exploratório realizada na internet e de visitas a feiras de equipamentos médico hospitalares. Ao final dessas análises preliminares, percebeu-se que o processo criativo que iria gerar o produto final era claramente diverso daquele seguido pelos caminhos da criação de produtos de natureza e complexidade mais simples. 
O desenvolvimento do projeto em questão foi planejado para ocorrer seguindo cinco fases e suas respectivas atividades: Fase 1: Conceito e Desenvolvimento Técnico do Projeto do Produto: Pesquisa de Mercado, Pesquisas/Entrevistas com Usuários e Operadores, Definição das Especificações Técnicas e Formais do Produto; Fase 2: Desenvolvimento do Processo do Produto: Análise e definição da capacidade produtiva a ser empregada na fabricação do novo equipamento: processos de fabricação, materiais e recursos produtivos; Fase 3: Produção de Modelos Virtuais, de Mock Ups e de Modelo Físico do Produto: Produção de Modelos Virtuais por meio de Modelagem 3D, A submissão dos modelos virtuais à Simulação e Análise por Elementos Finitos, A produção de Mock Ups, A construção de Modelos Físicos do Produto; Fase 4: Avaliação de Mock Ups e de Modelo Físico do Produto: A realização de testes simples para a avaliação dos Mock Ups e a realização de testes em laboratório credenciado com os Modelos Físicos do Produto para se obter a Certificação do Produto; Fase 5: Organização do Projeto para Produção: A Finalização de Desenhos Técnicos, Finalização do Manual do Usuário, Registro de Desenhos Industriais e/ou Patentes dos produtos e sistemas desenvolvidos, A entrega de um Protótipo do Produto.

O nome da empresa investidora e os detalhes de caráter técnico formal deste projeto não serão apresentados neste artigo por questões de sigilo estabelecidas em contrato assinado entre as partes envolvidas.

É sabido que designers industriais, através de seus cursos de bacharelado, devem adquirir condições intelectuais e criativas para compreender as necessidades daqueles para os quais trabalham ou para quem eles projetam - as indústrias, e, sobretudo, os que compram, ganham, utilizam o produto industrial. Estes desenvolvem a empatia, ou seja, apresentam condições emocionais de se pôr no lugar ora daquele que investe na fabricação de um produto, ora na posição de usuários de artefatos (e.g., aparelhos pessoais) ou de sistemas (e.g., serviços públicos), evitando, assim, a orientação criativa meramente voltada para o mercado de "produtos de consumo".

"Complexidade", simplificadamente, é a multiplicidade de elementos correlatos. No produto "Cama Hospitalar Eletromecânica" é incompleto classificar o projeto como sendo complexo, apenas por apresentar múltiplos desafios tecnológicos. Em projetos desta natureza existem outras questões que aumentam a complexidade do planejamento e que nem sempre podem ser respondidos com a aplicação adequada da tecnologia. É o caso da disponibilidade de uma equipe que esteja completa e homogeneamente capacitada.

Outra fonte geradora de potenciais dificuldades no projeto e que não tem correlação direta com a tecnologia nele empregada é a que trata da forma de se obter o financiamento do projeto, uma vez que os valores envolvidos no desenvolvimento deste porte tendem a ser substanciais. Aumentam, ainda, a complexidade do projeto fatores como a durabilidade do produto que, independentemente de seu satisfatório funcionamento, é algo considerado básico.

Como se trata de um produto de capital e, portanto, também é um bem industrial, a cama hospitalar aqui referida não pode ser tratada como item descartável. É preciso lembrar que um produto de Alta Complexidade Tecnológica (ACT) sempre virá acompanhado de outros produtos e serviços, derivados da sua própria natureza funcional e morfológica. Esclarecendo: é necessária a produção de um manual de uso 
para aqueles que a compram e/ou a utilizam; de material de treinamento para os técnicos de manutenção e para seus revendedores; o planejamento de fornecimento de partes de reposição mais frequente com acesso rápido e fácil para a sua troca e que possam ser obtidas com facilidade. Estes procedimentos "viscerais" e de manutenção pouco têm a ver com preocupações estéticas, mas, se bem explicitados podem ser uma poderosa ferramenta de marketing. Procedimentos não são um mero apêndice, mas fazem parte integrante do projeto de um produto.

Específicas a este projeto, incidem sobre ele normas e procedimentos de segurança e saúde, extremamente exigentes. O atendimento a estas normas, necessário para a certificação do produto vão muito além daquilo que em outros produtos industriais, com menos importância capital, pode ser resolvido com uma tabela de medidas antropométricas, e, por vezes, nem isso. Portanto, um desafio de maiores proporções é gerenciar este número de fatores diversos além da resolução de problemas de ordem funcional e estética.

No caso de equipamentos médico-hospitalares, podemos ter enorme classificação sistemática, para produtos nos quais o designer industrial, certamente tem cadeira cativa em seu desenvolvimento. $E$, entre tais produtos, encontra-se a cama hospitalar. Este produto, diacronicamente, sofreu significativas alterações e mudanças substanciais no desenho de sua forma, o que enfatiza fatores antropológicos (ideias e comportamento). Todavia, é no tempo presente (sincronia) que se observam diferenças consideráveis, particularmente, desde questões ergonômicas, (conforto/adequação), até as mercadológicas (preço/promoção), passando, indubitavelmente, pela tecnologia (materiais de produção/processos de fabricação). Percebe-se bem isto, quando se observam as mudanças nos modelos, resultantes do desenho de três tipos de camas hospitalares (BCT; MCT; ACT), todas, atualmente, à venda no mercado (Figura 1 ).

(A)
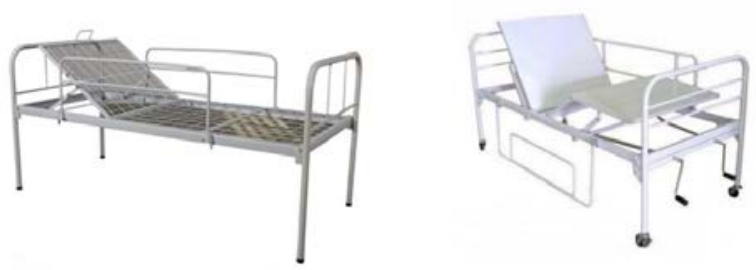

(B)

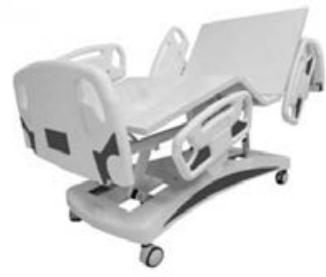

(C)

Figura 1 - Camas hospitalares de baixa, média e alta complexidade tecnológica: (a) Cama Hospitalar c/grade s/colchão padrão (2,04×90x60cm); (b) Cama Hospitalar Fowler 2 Acionamento Manual; (c) Cama Hospitalar 8 Movimentos Motorizada Luxury Clean.

Fonte:https://www.grupobond.com/camas-manuais/74-cama-hospitalar-fawler-2-movimentosmanual.html?gclid=CKTK56jJz8wCFcQIkQodsplOvw. Adaptado pelos autores.

O projeto da cama hospitalar, neste artigo, segue a linha de produtos que se assemelham à ilustração (C) da Figura 1, logo um produto de alta complexidade tecnológica. Em projetos dessa natureza, ACT, exige-se tanto por parte de empresários e gestores de projeto, quanto por parte dos projetistas (designers ou não), o domínio de técnicas analíticas de produto industrial (Cf. BONSIEPE, 1978; LOBACH, 2001; 
SANTOS \& HORTA, 2005), para adquirir-se consciência de seis (Cf. REDIG, 1977/2005) ou de nove (Cf. ARCHER, 1965/apud CROSS, 1984) fatores projetuais.

Bruce Archer, como exemplo clássico para produto cama hospitalar, recomenda que às seguintes categorias de fatores projetuais, observem-se, entre parênteses, as relevâncias: 1. Estética (uso/vendas); 2. Motivação (uso/vendas); 3. Função (uso/vendas); 4. Ergonomia (uso); 5. Mecanismos (uso/fabricação); 6. Estrutura (uso/fabricação); 7. Produção (vendas/fabricação); 8. Economia (vendas/fabricação); 9. Apresentação (vendas) (ARCHER, apud CROSS, 1984, p.62).

Pergunta-se: Como resolver questões de responsabilidade no projeto de produto? Responde-se: Valendo-se de uma série de ferramentas teóricas, porque intelecto-criativas, e também da exploração de processos lógicos, inovadores, sempre levando em consideração a dimensão temporal, constituindo o que podemos chamar de Procedimentos + Técnicas. Destarte, (i) fazendo empréstimo de nomenclatura de Russel (2001); (ii) ordenando influência denominada por Bonsiepe (1984); e (iii) reforçando ciência impressa por Friedman (2015), esses conjuntos de "Procedimentos \& Técnicas" (P\&T) devem ser agrupados em três distintos grupos: (10) METÓDICAS GERAIS-P\&T de natureza comum, pois podem ser usados por vários tipos de designers (e.g., engenheiros, arquitetos e desenhadores); $\left(2^{\circ}\right)$ METODOLOGIAS ESPECÍFICAS -P\&T de condição exclusiva às habilitações do Design (e.g. Engenharia Mecânica; Arquitetura Habitacional; Desenho Industria); $\left(3^{\circ}\right)$ MÉTODOS PECULIARES -P\&T de uso típico ao desenho de certos produtos, suas partes, componentes, elementos (e.g., projeto para desenho de camas hospitalares, de colchões higiênicos, de interfaces gráfico-visuais para acionamento de controles dos mecanismos).

Joaquim Redig, dez anos depois, sintetizou-os, em língua portuguesa, para seis fatores projetuais. A proposta de Redig apresenta nomenclatura mais uniforme, e, ainda, consegue encaixar os fatores projetuais em definição bem apropriada: "Desenho Industrial (Design) é o equacionamento simultâneo de fatores ergonômicos, perceptivos, antropológicos, tecnológicos, econômicos, e ecológicos, no projeto dos elementos e estruturas físicas necessárias à vida, ao bem-estar e/ou à cultura do homem" (REDIG, 1977/2005, p.32).

Foi, contudo, Archer que salientou que "na prática, claro, o desenhador não pode definir os fatores com base em seus problemas particulares, simplesmente em termos dessas listas. Um problema simples de projeto é um complexo de centenas ou mais subproblemas. Cada subproblema pode ser abordado de maneira característica, i.e., pesquisa operacional, desenhos e debuxos, análise de valor etc. Embora, porém, cada subproblema possa ser resolvido até se chegar a uma solução ótima ou mesmo a um campo de soluções aplicáveis, a parte complicada da tarefa é reconciliar as soluções dos subproblemas umas com as outras. Geralmente, onde a solução ótima de um subproblema tende a aceitar uma solução simples de outro subproblema, o desenhador é forçado a decidir qual das duas soluções deve ser tomada como prioridade. (Tradução dos autores a partir de ARCHER, 1965, apud CROSS, 1984, p.62).

Antes, porém, de retornarmos a Bruce Archer, vale ressaltar algo dito por Gui Bonsiepe, há mais de 30 anos, com respeito a projetos de produto em Design Industrial, particularmente, àqueles referentes ao desenho de produtos complexos: Os conjuntos de procedimentos e técnicas que o designer industrial tem ao seu dispor, "não deve ser confundido com um livro de receitas de bolo" (BONSIEPE, 1984, p.34) 
Métodos de Desenho para fins de uso na prática do Design Industrial não podem ser misturados ou confundidos com os Métodos Científicos, "super métodos", atitudes intelectuais estruturalistas, dialéticas, como ensinaria Bonsiepe, em 1984. Tampouco, podem ser tomados como "micro métodos", ou seja, normas, regulamentos, truques, regras e, como já foi ressaltado, receitas para a uma prática projetual bem-sucedida. As ferramentas teóricas referentes às atitudes e comportamentos do designer industrial, e aos procedimentos e técnicas auxiliares à prática do projeto de produto em Design Industrial, tratam-se de estratégias intelectuais e criativas, não apenas para identificar situações de desajuste relativos aos problemas projetuais, mas, sobretudo, auxiliares de memória à condução de raciocínio no processo de decisão, no controle de variáveis e da geração de soluções no projeto de produtos complexos.

Archer perguntaria: "Por que, então, ficamos aborrecidos em falar sobre métodos sistemáticos de projetação? O fato de ser sistemático não é necessariamente sinônimo de ser autômato. A ciência da computação é um bom exemplo de abordagem sistemática e lógica na solução de problemas projetuais. No campo do Design Industrial, dizer-se ia, verdadeiramente, que tendo um problema projetual sido preparado por um computador, a resposta quase sempre tornar-se-á tão óbvia para um habilidoso desenhador que ele dispensará os serviços do próprio computador. Claro que isso nem sempre trará a certeza de que a resposta obtida seja a melhor ou a única, todavia, uma vez que raramente ele é chamado a prová-la, se a resposta funcionar ela será suficiente". (Tradução livre de ARCHER, 1965, apud CROSS, 1984, p.63, feita pelos autores.)

Cabe ao designer industrial, ainda com base em Archer, diante de situações complexas, definir os "subsistemas em ordem de importância". Uma das primeiras ações, depois de compreendido o briefing ou, melhor, o (i) Arrolamento de Atributos para desenho do produto; o Rol de Restrições para o projeto de produto; e a Lista de Verificação do processo projetual, é a feitura de um mapa mental. Esse mapa terá a função de permitir a visualização das relações entre as partes e subpartes, os sistemas e subsistemas, de um projeto de produto complexo.

Em seguida, deve-se encontrar bibliografia cujos autores tenham agrupados Procedimentos + Técnicas gerais que configurem metódicas auxiliares à memória de todos os profissionais de vários campos de atuação do Design (e.g., JONES, 1970; CROSS, 1984; BÜRDEK, 1994; BOMFIM, 1995; BAXTER, 1998; DUBBERLY, 2004). Certamente, esses livros hão de oferecer condições à compreensão de quais metódicas configuram utilidade ao projeto de produtos complexos.

Se a primeira ação - mapa mental - é de cunho privado do designer industrial, a segunda e a terceira ação - cronograma de trabalho e escolha de tipo de modelo metodológico para o projeto de produto complexo - é fruto de reuniões de projeto com integrantes da equipe, tal como Dreyfuss sugeria, em 1955. E, mais. O cliente tem que estar obrigatoriamente ciente de todas essas decisões. $E$, no caso do projeto, aqui em foco, um instituto de tecnologia pertencente à administração direta do governo federal do Brasil, foi a instituição que, justo por seu caráter multidisciplinar, acolheu tal projeto de produto complexo através de sua divisão de desenho industrial. Isto não se deu de modo acidental. Este instituto, valendo-se de seus conhecimentos sobre tecnologia industrial, possui laboratórios que são referências nacionais em suas áreas de atuação, e tem sistema de qualidade único, acreditado pelo Inmetro. 


\subsection{Custo de Projeto para Produto de Alta Complexidade Tecnológica (ACT)}

O presente projeto da cama hospitalar já se encontra em fase de finalização. Contudo, como já dito na introdução deste artigo, o nome da marca-de-comércio da empresa investidora e de detalhes do desenho do produto não serão apresentados por questões de sigilo contratual. Isto, certamente, não afeta os objetivos deste artigo: as relações de conhecimento entre os membros da equipe de desenvolvimento de projeto.

Como vimos na Figura 1, os exemplos de camas hospitalares têm mudado significativamente seus paradigmas. A cada modelo lançado no mercado, materiais, funções de uso, acabamentos estéticos e higiênicos, manutenção e manuseio, dentre outros, são, convergentemente, alterados a cada série produzida. Entretanto, mudanças de paradigmas tecnológicos, como aqueles para o pleno funcionamento mecânico da cama através de controles, sejam esses acionados por força muscular ou, eletronicamente (uma tendência atual) divergem criativamente de tal modo, a ponto de estabelecerem novos paradigmas, capazes de por si só aumentarem as vantagens competitivas desse produto de capital no mercado. O que interessa aqui reportar, porém, é que seja essa uma cama simples e básica (BCT), seja ela capaz de oferecer um pouco mais de conforto ao paciente (MCT), tais produtos exigem que seu desenvolvimento seja feito junto a órgãos governamentais que normalizam e certificam seus projetos.

O projeto de camas hospitalares de ACT não é um design autoral, mas um complexo projeto de produto que, devido a sua qualidade estético-formal, lógicoinformacional e técnico-funcional, deixa de ser uma "mercadoria" e passa a ser um "bem" da cultura material, da civilização que o projetou. E, mais, um bem industrial capaz de indicar as ideias desse projeto em elegantes linhas de belo desenho industrial.

E isto, sim, é muito importante, principalmente, sob a ótica econômica. Em seu livro Design Awareness and Planned Creativity (1965) e reeditado no Canadá em 1974, Bruce Archer apresentou os Estágios para o Planejamento Estratégico de produtos de Design Industrial e, pelo detalhamento, produtos de ACT (1974, p.46). Nele, Archer ressalta que o custo nos estágios iniciais do projeto varia de 5 e 20 por cento do total do custo de projeto. $E$, mais, que nos estágios finais, propriamente o Desenvolvimento de Produto, que envolvem equipes de alto nível interdisciplinar, esse percentual pode variar de 40 a 60 por cento do custo total de projeto. Logo, algo que requer muito planejamento da política de produto, muita organização das equipes de projeto, e, sobremaneira, bastante capacidade intelecto-criativa no desenvolvimento do produto.

Por isso, a parceria para o desenvolvimento desta cama hospitalar em particular surgiu com a possibilidade de ele ser realizado por meio de recursos financeiros obtidos via Projeto EMBRAPII - Empresa Brasileira Pesquisa e Inovação Industrial - associação qualificada como uma Organização Social pelo Poder Público Federal e que tem como missão contribuir para o desenvolvimento da inovação na indústria nacional através do fortalecimento da colaboração desta com institutos de pesquisas e universidades do Brasil. Isso colocava a possibilidade de financiamento de um terço do seu custo com recursos provenientes do governo federal via Confederação Nacional da Indústria (CNI). O fabricante arcaria com outro terço e o referido instituto de pesquisa arcaria com o terço restante. 


\subsection{Equipe de Projeto Fixa para Produto de Alta Complexidade Tecnológica (ACT)}

A equipe de projeto fixa era composta de distintos profissionais. Destacam-se: Um designer industrial sênior, com responsabilidades sobre: Gerenciamento do Projeto; Pesquisa de Mercado; Entrevistas com usuários; Desenho de Produto; Análise da Usabilidade (segundo Normas da ABNT). Um engenheiro de produção encarregado do Apoio no Gerenciamento do Projeto; Pesquisa de Mercado; Análise do Fluxo de Produção; Supervisão da Produção de Mocapes e Protótipo. Um engenheiro gestor de projetos designado para: Apoio no Planejamento do Projeto; Pesquisa de Mercado; Entrevistas com usuários e Análise; Estudo das Normas e apoio na sua implementação; Planejamento do Gerenciamento de Riscos do Produto; Preparação do Teste de Usabilidade do Produto segundo Normas ABNT. Um (bolsista) designer industrial júnior, auxiliar para a Pesquisa de Mercado; Estudo da Norma Particular; Desenho de Produto;

Modelagem 3D virtual (gráfica computacional); Análise da Usabilidade do Produto segundo Normas ABNT. Um (bolsista) desenhista técnico responsável pela Pesquisa de Mercado; Estudo da Norma Particular; Desenho de Produto; Processamento digital 2D/3D; Análise da Usabilidade do Produto segundo Normas ABNT; Formatação de Manual de Operação da Cama Hospitalar. Um (bolsista) designer gráfico responsável por Estudo da Norma Particular; Processamento digital 2D/3D; Análise da Usabilidade do Produto segundo Normas ABNT; Formatação de Manual de Operação da Cama Hospitalar. Paralelamente foram contratados os serviços de três consultores engenheiros mecânicos e cada um com um objetivo a ser atendido: (a) um especialista no desenvolvimento de peças em polímero para apoiar a equipe no projeto das peças que seriam produzidas em material plástico; (b) um especialista para simular por meio da Análise Numérica por Elementos Finitos o comportamento da estrutura metálica da cama para que se pudesse avaliar e consolidar essa parte do projeto antes de se iniciar o seu detalhamento para fabricação; (c) um apontador de soluções para os problemas de rigidez da estrutura da cama detectados após a avalição do seu mocape e não identificados durante a simulação feita pela Análise Numérica por Elementos Finitos.

O projeto envolveu vários processos de sistematização, ou seja, tratava-se de produto que apresentava grande número de componentes e elementos de máquinas (tubos e perfis, parafusos e porcas, atuadores eletromecânicos etc.). Além disso, as pesquisas exigiram especificações técnicas mais complexas e sofisticadas em termos de detalhamento, fosse do ponto de vista de sua concepção e também da produção de mocapes, protótipos e do registro gráfico do projeto.

O projeto de Alta Complexidade Tecnológica, uma cama hospitalar eletromecânica, tomado neste artigo para exemplificar como se aproximar a prática da projetação com a teoria do projetar, ainda que sem permissão legal para se dar mais detalhes sobre o seu desenvolvimento, trata-se de relato de vivências no desenvolvimento de um produto de ACT. Aqui, ressalta-se que Design Industrial não é atividade para se projetar produtos sem a noção do todo cultural, técnico e normativo em que se insere. Assim o DI, em projetos de impacto social, não trata de desenhar detalhes de estética duvidosa, mas, sim, tecnologicamente, de precisar as variáveis, cabíveis de controle, pois é profissão fecunda e de trabalho em equipe.

Notou-se, assim como também se notou em outros projetos que foram anteriormente acompanhados pelos autores deste artigo, que as equipes de projetistas envolvidas em projeto de tamanha relevância para a cultura material 
brasileira, além do pouco conhecimento e da pouca prática no uso de metodologias para projetos de produtos de capital, dificilmente integravam as capacidades e habilitações para os vários atores presentes no desenvolvimento interdisciplinar de projeto, despreparadas que estavam para compreenderem seus respectivos papeis em reuniões de projeto integradas. No caso do designer industrial, em 2016, para se tornar verdadeiro Líder de Projeto (LP), melhor estudar para saber como se posicionar em projetos complexos perante uma equipe interdisciplinar de projeto de produto qualificará o designer industrial plenamente para as Reuniões de Projeto. Na Figura 2, observa-se o quanto o Líder de Projeto (LP) deverá possuir de conhecimentos e saberes, antes mesmo de demonstrar todas as suas habilidades como designer industrial.

\begin{tabular}{|c|c|c|}
\hline \multicolumn{3}{|c|}{ Conhecimentos/Saberes $\quad$ GE I PP | LP | PL | CP | IE } \\
\hline \multicolumn{3}{|c|}{ Planejamento estratégico e plano } \\
\hline \multicolumn{3}{|c|}{ Metas estratégicas da organizaçäo } \\
\hline \multicolumn{3}{|c|}{ Tomadas de decisão e projeto } \\
\hline \multicolumn{3}{|c|}{ Interpretação de dados/informações do projeto } \\
\hline \multicolumn{3}{|c|}{ Habilidades de liderança no projeto } \\
\hline \multicolumn{3}{|c|}{ Comunicação oral/gráfica (verbal \& visual) } \\
\hline \multicolumn{3}{|c|}{ Planejamento de projetos de produtos } \\
\hline \multicolumn{3}{|c|}{ Gerência de reuniões de projeto } \\
\hline \multicolumn{3}{|c|}{ Metodologia organizacional de projeto } \\
\hline \multicolumn{3}{|c|}{ Conhecimento de práticas em projeto produto } \\
\hline \multicolumn{3}{|c|}{ Planejamento de gerência de cronograma } \\
\hline \multicolumn{3}{|c|}{ Gerência da qualidade do projeto } \\
\hline \multicolumn{3}{|c|}{ Planejamento e gerência de custos/orçamento } \\
\hline \multicolumn{3}{|c|}{ Planejamento e gerência de riscos do projeto } \\
\hline \multicolumn{3}{|c|}{ Planejamento e gerência de recursos humanos } \\
\hline \multicolumn{3}{|c|}{ Planejamento e gerência de aquisições projeto } \\
\hline \multicolumn{3}{|c|}{ Funções e responsabilidades da equipe de projeto } \\
\hline \multicolumn{3}{|c|}{ Projeto/desenho e uso de ferramentas teóricas } \\
\hline $\begin{array}{l}\mathrm{GE}=\text { Gerente Executivo } \\
\mathrm{PP}=\text { Potrocinador do Projeto } \\
\mathrm{LP}=\text { Lider do Projeto }\end{array}$ & $\begin{array}{l}\mathrm{PL}=\text { Planejador do Projeto } \\
\mathrm{CP}=\text { Controlador do Projeto } \\
\mathrm{IE}=\text { Integrante da Equipe }\end{array}$ & $\begin{array}{l}\text { CLELAND, David 1.; IRELAND, Lewis R. } \\
\text { Gerência de Projetos. Rio de Jineirc } \\
\text { Reichmann \& Affonso, 2002, 0.48/49 }\end{array}$ \\
\hline
\end{tabular}

Figura 2 - Conhecimentos e Saberes.

Fonte: CLELAND, David I.; IRELAND, Lewis R. Gerenciamento de Projetos. Rio de Janeiro: Reichmann \& Affonso, 2002, p.48-49. Adaptado pelos autores.

\section{CONCLUSÃO}

No desenvolvimento de um produto de Alta Complexidade Tecnológica (ACT) a Gestão de Projeto é fundamental para que o designer industrial se posicione como o Líder de Projeto (LP), deixando de atuar apenas como mero produtor de belas ilustrações das ideias alheias.

Designers industriais devem estar alertas contra ações, muitas vezes equivocadas, de terceiros sobre seus processos decisórios. Portanto, e como já mencionado anteriormente, caberá ao designer industrial, diante de situações complexas, como as encontradas no projeto de uma cama hospitalar eletromecânica, inicialmente definir quais os subsistemas, em ordem de importância, que serão o alvo de seu plano de trabalho. Trabalhará com algumas condicionantes inflexíveis de projeto e outras que o designer plasmará. Para isso ele deverá se valer de uma série de ferramentas teóricas, e intelecto-criativas, que combinam em si dezenas de conjuntos de Procedimentos + Técnicas orientadores como um "sistema auto organizado" à criação (cf. JONES, 1972/1982, p.55); e de exploração de processos lógicos, criativos, de avaliação e de controle de tempo (cf. BOMFIM, 1995). Este comportamento 
projetual deverá acompanhar cada fase do projeto, sendo flexível para digerir novos insumos, estabelecer novas hierarquias e corrigir rumos, quando necessário.

\section{REFERÊNCIAS}

ARCHER, Bruce. Systematic Methods for Designers. London: Council of Industrial Design, 1965.

ASIMOW, Morris. Introduction to Design. Englewood Cliffs: Prentice-Hall, 1962.

BARROSO NETO, Eduardo (Org.). Desenho Industrial: Desenvolvimento de Produtos. Brasília: Coord. Editorial CNPq, 1982.

BAXTER, Mike. Projeto de Produto. São Paulo: Edgard Blucher, 1998.

BOMFIM, Gustavo Amarante. Desenho Industrial: proposta para reformulação de currículo mínimo. 1978. 133f. Tese (Mestrado, MSc) apresentada ao Programa de PósGraduação em Engenharia de Produção da Universidade Federal do Rio de Janeiro.

BOMFIM, Gustavo Amarante et al. Fundamentos de uma Metodologia para Desenvolvimento de Produto. 1977. 105f. Trabalho de pesquisa no campo da metodologia para desenvolvimento de projetos. Programa de Pós-Graduação em Engenharia de Produção da Universidade Federal do Rio de Janeiro.

BOMFIM, Gustavo Amarante. Metodologia para Desenvolvimento de Projetos. Campina Grande: Ed. UFPB, 1995.

BONSIEPE, Gui. Diseño Industrial: Artefacto y Proyecto. Madrid: Alberto Corazon, 1975.

BONSIEPE, Gui. Teoría y Práctica del Diseño Industrial. Barcelona: Gustavo Gili, 1978.

BONSIEPE et al. Metodologia Experimental: Desenho Industrial. Brasília: Coord. Editorial CNPq, 1984.

BONSIEPE, Gui. Desenvolvimento pelo Design. In PATROCíNIO, G.; NUNES, J. M. (Org.). Design e Desenvolvimento 40 Anos Depois. São Paulo: Blucher, 2015 (p.229-250).

BÜRDEK, Bernhard. Diseño: história, teoria y práctica del diseño industrial. Barcelona: Gustavo Gili, 1994.

CLELAND, David I.; IRELAND, Lewis R. Gerenciamento de Projetos. Rio de Janeiro: Reichmann \& Affonso, 2002

CROSS, Nigel (Ed.). Developments in Design Methodology. Chichester: John Wiley\& Sons, 1984.

DORFLES, Gillo. II Disegno Industriale e la sua Estetica. Milano: Cappelli, 1963.

DREYFUSS, Henry. Designing for People. 1st edition, 1955. New York: Allworth, 2003.

DUBBERLY, Hugh. How do You Design? San Francisco: Dubberly Design Office, 2004. <http://www.dubberly.com/articles/how-do-you-design.html . Acesso 25 maio 2016.

FERREIRA, Manoel Francisco. O Desenho Industrial: sua importância para a arte decorativa. 1967. 38f. Tese de Concurso (Docente Livre) da Cadeira de Arte Decorativa da Escola de Belas-Artes da Universidade Federal do Rio de Janeiro. 
FIELL, Charlotte; FIELL, Peter. Design Handbook: concepts, materials, styles. Köln: taschen, 2006.

FRIEDMAN, Ken. Research Writing Workshop. Shanghai, China: College of Design and Innovation, May 2015. (From: Ken Friedman, To: PHD-DESIGN@JISCMAIL.AC.UK. 26/05/2015 01:46 (GMT-03:00). Subject: Method, Methodology, Methodics)

JONES, Christopher J. Design Methods. 2nd edition. New York: John Wiley\& Sons, 1992.

LOBACH, Bernd. Design Industrial: bases para a configuração de produtos industriais. São Paulo: Edgard Blucher, 2001.

MONTENEGRO, Gildo Azevedo. O Desenho Técnico na Fabricação. 1964. 43f. Tese de Concurso (Livre Docência) para Cadeira de Desenho Técnico - Escola de Belas Artes da Universidade de Recife, Curso de Professorado de Desenho.

REDIG, Joaquim. Sobre Desenho Industrial: desenho de produto, comunicação visual. 1 edição, 1977. Porto Alegre: Ed. UniRitter, 2005.

RUSSEL, Bertrand. História do Pensamento Ocidental. São Paulo: Ediouro, 2001.

SANTOS, Teresa; HORTA, Luís. A Cama Hospitalar para Adultos. Cadernos DGIES N ${ }^{\circ} 6$ Lisboa: Ministério da Saúde, dezembro de 2005, p.3 